\title{
Genetic Nurses and Counsellors - Preparation for Practice with Families at Risk of Familial Cancer
}

\author{
Heather Skirton ${ }^{1,2}$ \\ ${ }^{1}$ Clinical Genetics Unit, Taunton and \\ Somerset NHS Trust, UK \\ ${ }^{2}$ School of Psychology, University of Exeter, \\ $U K$
}

Genetic counselling for familial cancer has evolved as a medical speciality relatively recently. Whilst services for families at risk of inherited cancers may be similar to those offered to other families at risk of serious adult-onset conditions, the resource implications are larger due to the number of families potentially affected. Genetic counsellors can make a considerable contribution to the provision of genetic services for these families.

In a longitudinal study of 43 families referred for genetic counselling for a variety of conditions (including cancer), the needs and expectations of clients were explored. Prior to contact with the staff of the genetics service, the majority of families had no knowledge of the genetics service, or of the process referred to as genetic counselling. They therefore had no idea of the type of service which could be offered to them and they were inadequately prepared by the person who referred them. One factor which emerged strongly as an important influence in motivating clients to request genetic information was the client's need for certainty. The need for certainty is considered a personal trait which may vary enormously between individuals [8]. Clients in this study who were asking for information felt that any news, either "good" or "bad" was preferable to living with uncertainty
[4]. This finding is of relevance to clients at risk of familial cancer. Even those who have a positive gene test will usually be left with some uncertainty due to factors such as variable penetrance. A second important finding was evidence that individuals construct their own explanation about the inheritance of the condition, based on both the family history and information from other sources such as friends, the media and other health professionals. Whilst prior "scientific" knowledge of genetic inheritance was scant in most families, the "lay" knowledge was strongly held. In order for the genetic information to be assimilated into the individual's construct of the genetic condition, the scientific explanation must be seen to be consistent with the family story, or it may be rejected by the client as suspect. The results of the study indicate clients want information which will give them more certainty about their situation, and that scientific information given during the process of genetic counselling needs to be presented in a way that enables the client to assimilate it into their previous beliefs, by relating it to their own family history.

In the United Kingdom, genetic services are provided by a multi-disciplinary team which includes medical geneticists and non-medical genetic counsellors, based at Regional Genetics Centres. The majority of genetic counsellors have nursing background. Frequently, the genetic counsellor will initially visit the family at home to take the family history and discuss the main concerns. Further consultations with either the counsellor, and/or the medical staff may then occur, according to the needs of the family. Data collected in a UK study on the role of the genetic 
counsellor indicated that both medical and nonmedical genetic staff considered it appropriate for genetic counsellors to provide services to families, especially in conditions where the diagnosis was firmly established [6]. Genetic counsellors were regarded as an integral part of a multi-disciplinary team, with particular skills in helping clients deal with the psychosocial aspects of the condition.

Within the realm of cancer genetics, the genetic counsellor is able to initiate contact with the family, obtain a pedigree, obtain consent from living relatives to access their medical records, confirm relevant medical history, advise family members with regard to their risks and options, provide information, and arrange clinical screening and follow-up. There is ample research evidence that psychological difficulties may be experienced by individuals at increased risk of cancer. They may feel that cancer is inevitable, whatever the numerical risk [1]. Anxiety may be not be reduced by test results, even if normal [2]. Families who are seeking genetic counselling to obtain additional clinical screening may be unable to accept a low risk assessment which denies them that means of reassurance [3]. As the condition causes premature death in the family, grief issues are frequently prominent and the family may need to discuss their feelings of loss and anxiety about the future to enable them to focus on the genetic issues. In addition, the counsellor needs to explore the family's beliefs about the inheritance pattern and provide explanations which enable them to put the information into their own specific context. If this is not achieved, there may be implications for future decisions about testing, reproduction and compliance with clinical surveillance regimes.

Within Europe, there is no system for the accreditation of genetic counsellors, nor a statutory training requirement for those working in the field. Formalised systems exist in both North America and in Australasia, and the feasibility of setting up an accreditation process is being examined by the Association of Genetic Nurses and Counsellors (AGNC) in the United Kingdom. Those working as genetic counsellors in the United Kingdom in familial cancer clinics may have a background in nursing, particularly oncology, or may have completed a Master's degree in genetic counselling. In other areas of Europe, such as the Netherlands, counsellors may be more likely to have a background in psychology or social work. In an attempt to establish guidelines for training and education for safe clinical practice, a Working Party of the AGNC published a series of recommendations. These were based on the results of the research study mentioned above on the role of the genetic counsellor. They include minimum training requirements in the four areas of vital importance: knowledge of human genetics, counselling skills, teaching skills and ability to interpret research [7]. A basic degree or other formal education in human genetics is considered to be essential, as is a basic training in counselling skills (not less than 120 guided learning hours). A qualification in teaching adults, and an ability to critique research are also recommended. However, it is emphasised that as clinical skills are largely acquired experientially, practical experience with structured supervision and formal feedback is also an integral part of the preparation for this role. It is also essential that, given the rapidly changing nature of this field, education is ongoing and practice must be constantly reviewed by audit, self-reflection and peer supervision.

With appropriate education and training, genetic counsellors have an important role in taking the scientific advances in the genetics of breast cancer, and making them comprehensible and useful to individuals at risk.

\section{References}

[1] Lynch, J. and Lynch, H.T. Genetic Counseling and HNPCC. Anticancer Research Vol 14, (1994) 1651-1656.

[2] McDonald, I.G., Daly, J., Jelinek, V.M., Panetta, F. and Gutman, J.M., Opening Pandora's box: the unpredictability of reassurance by a normal test result. BMJ 313(7053), (1996) 329-332.

[3] Richards, M.P.M. The new genetics: some issues for social scientists. Sociology of Health and 
Illness 15(5), (1993) 567-586.

[4] Skirton, H. and Eiser, C. Genetic counselling and the client's need for certainty. Poster presentation. 6th European Psychosocial Aspects of Genetics Meeting, Paris, France, September, 1998.

[5] Skirton, H. The impact of a genetic condition on the family. Poster presentation. International Society of Genetic Nurses Meeting, Denver, USA, October, 1998.

[6] Skirton, H., Barnes, C., Curtis, G. and WalfordMoore, J. The role and practice of the genetic nurse. J. Med. Genet. 34(2), (1997) 141-147.

[7] Skirton, H., Barnes, C., Guilbert, P., Kershaw, A., Kerzin-Storrar, L., Patch, C., Curtis, G. and Walford-Moore, J. Recommendations for education and training of genetic nurses and counsellors in the United Kingdom. J. Med. Genet. Vol. 35(5), (1998) 410-412.

[8] Webster, D.M. and Kruglanski, A.W. Individual differences in need for cognitive closure. $J$. Personality and Social Psychology. 67(6), (1994) 1049-1062. 


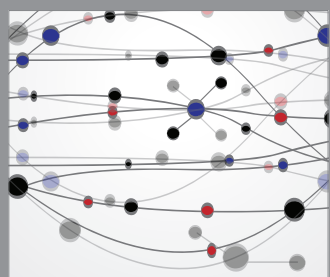

The Scientific World Journal
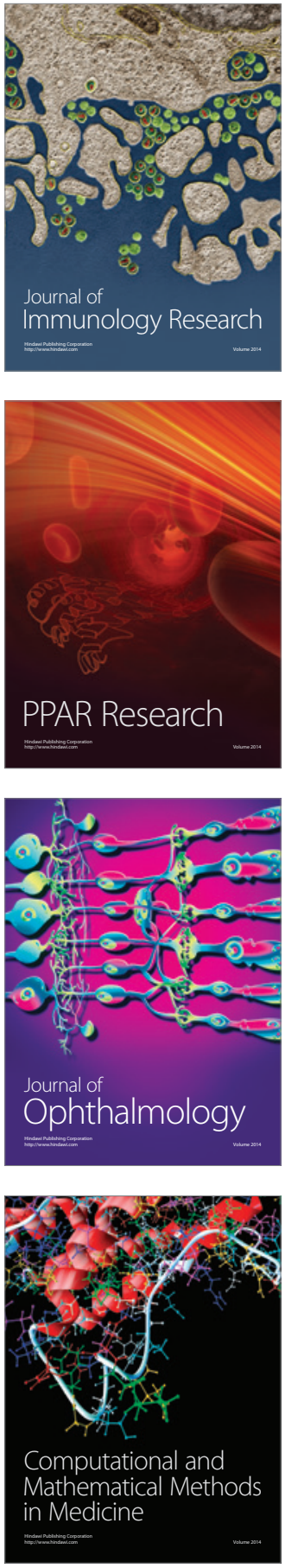

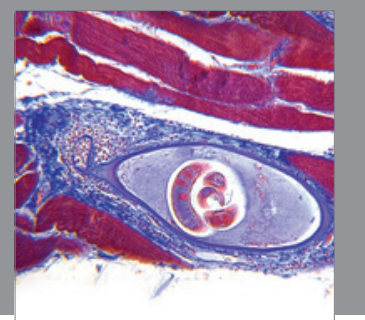

Gastroenterology

Research and Practice
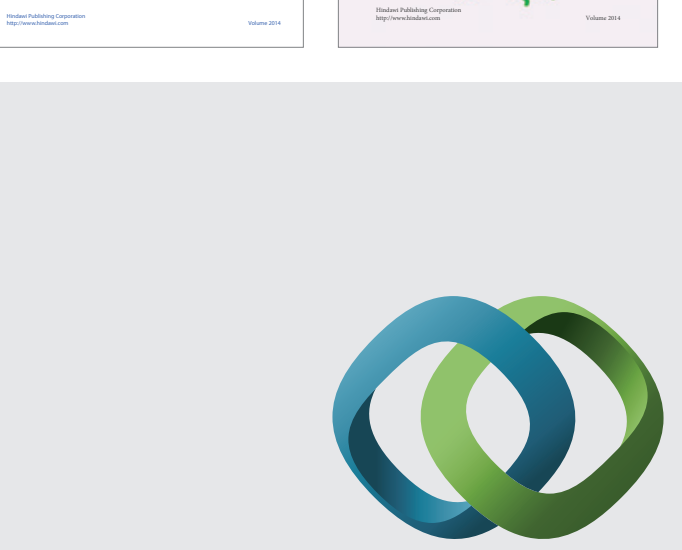

\section{Hindawi}

Submit your manuscripts at

http://www.hindawi.com
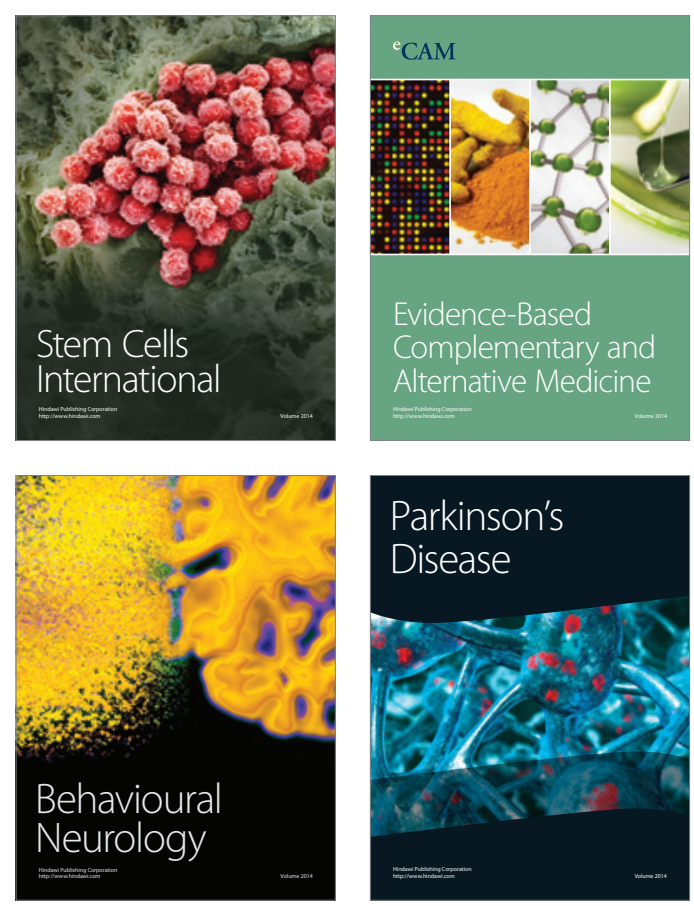

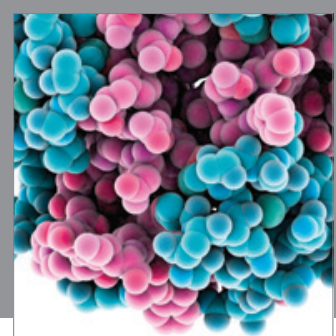

Journal of
Diabetes Research

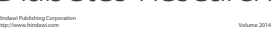

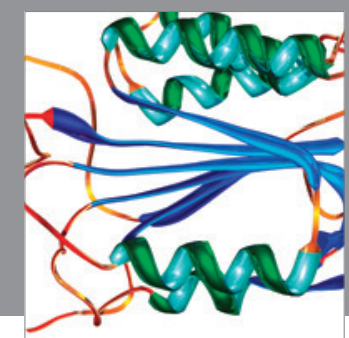

Disease Markers
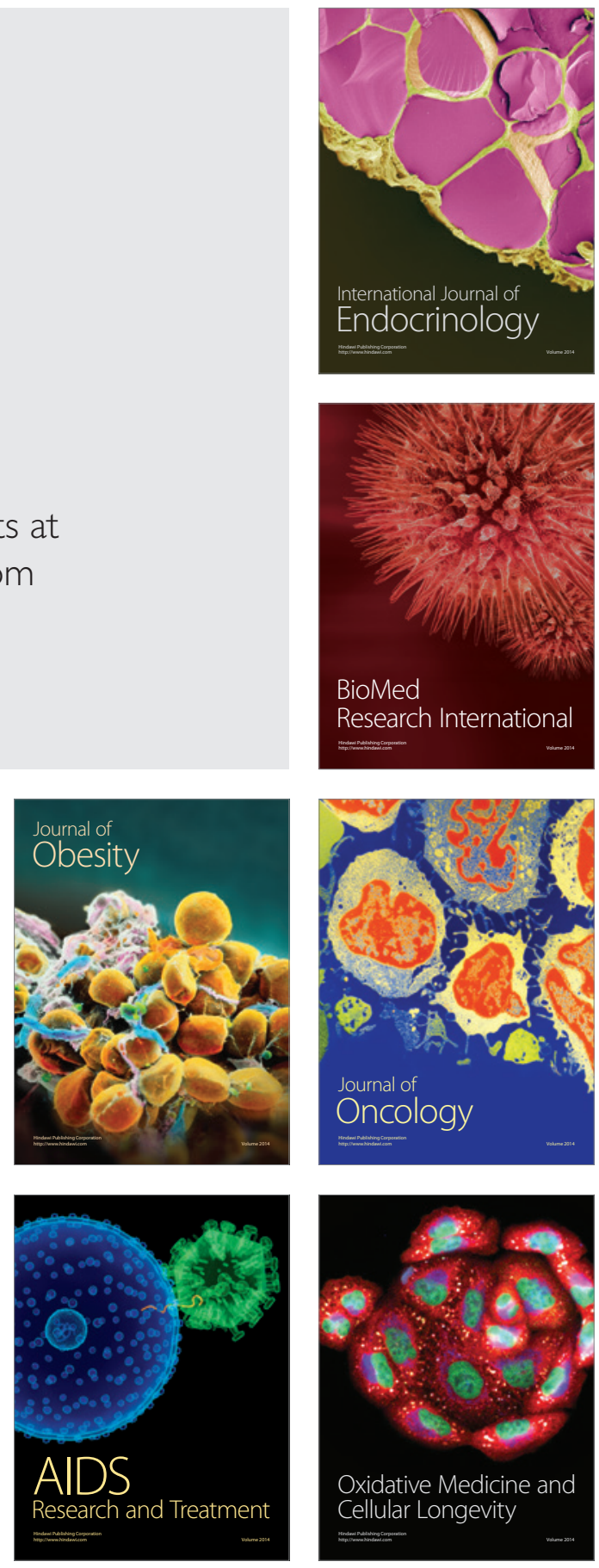